\title{
Um olhar engajado sobre a justiça alimentar e os Panteras Negras
}

Ewerton Reubens Coelho-Costa

RESENHA: BROAD, G. M. More Than Just Food: Food Justice and Community Change. Oakland, CA: University of California Press, 2016.

A obra More Than Just Food: Food Justice and Community Change, editada em língua inglesa em 2016 e ainda sem tradução no Brasil, contextualiza as mudanças sociais e referentes à justiça social a partir de questões sobre o acesso aos alimentos, tendo como foco grupos de justiça alimentar no sul da cidade de Los Angeles (EUA). O livro torna-se contribuição valiosa para pesquisadores das áreas ligadas à alimentação, comunicação, ciências sociais e direito, bem como para curiosos e ativistas ligados ao movimento de justiça alimentar.

O autor, Dr. Garrett Broad, é professor assistente do Departamento de Comunicação e Estudos de Mídia da Fordham University, em Nova Iorque. Suas pesquisas direcionam o foco para o papel das narrativas e da tecnologia de comunicação na promoção de movimentos em rede para a justiça social. Grande parte de seu trabalho concentra-se nos sistemas alimentares locais e globais, na medida em que ele explora como os alimentos podem contribuir para melhorar a saúde dos bairros, a sustentabilidade ambiental, os direitos e o bem-estar de pessoas e animais. Ele alerta sempre, em seus trabalhos, que existe uma crise acontecendo na América, resultando na distribuição injusta de alimentos saudáveis.

Fincada em pesquisa etnográfica realizada por Broad, que trabalhou voluntariamente na Community Services Unlimited

\section{Ewerton Reubens Coelho-Costa}

Doutorando em Sociologia pela Universidade Estadual do Ceará (UECE) e mestre em Gestão de Negócios Turísticos pela mesma universidade. E-mail: ewertonreubens@gmail.com 
(CSU), uma organização de justiça alimentar que surgiu do Partido Pantera Negra do sul da Califórnia, a obra analisa como a CSU, dentro de uma ecologia de comunicação em rede, busca equilíbrio com o cenário das mudanças sociais e tem comprometimento para manter a solvência fiscal. A organização também mantém seu foco em atender as necessidades da comunidade ao mesmo tempo em que precisa estar atenta às necessidades de movimentos nacionais e internacionais. Sua forma de comunicação e interação compreende moradores locais e públicos externos à comunidade. Aqui, observa-se que muitos grupos que exigem mudanças sociais no âmbito local encontram-se circundados por estruturas maiores, poderosas e ligadas à justificativa do desenvolvimento.

No primeiro capítulo, intitulado "Networks, Narratives, and Community Change", torna-se evidente a defesa pelo ativismo em nível comunitário como elemento fundamental na "era do neoliberalismo" (BROAD, 2016, p. 21) e a adaptação teórica das noções da perspectiva da ecologia da comunicação encontradas em Ball-Rokeach et alli (2012) e Wilkins et alli (2007), que analisam a rede de organizações de recursos de comunicação interagindo para prosseguir objetivos comuns. Neste capítulo inicial, ainda se descrevem cuidadosamente as ações que podem tornar uma organização de justiça alimentar bem-sucedida, como oportunizar transformações políticas e culturais, possuir redes de parcerias entre setores da comunidade e fundamentalmente se contar histórias sobre comida e justiça social.

O segundo capítulo, de título "Food Systems, Food Movements, Food Justice", contextualiza o panorama do sistema alimentar da contemporaneidade e os movimentos alternativos ligados à alimentação. Aqui se encontram severas críticas a projetos de movimentos ligados à alimentação nos Estados Unidos. A partir desses movimentos, se observa o favorecimento de escolhas apolíticas individualizadas do consumidor em detrimento de abordagens centradas na comunidade, as quais reconhecem as razões estruturais por trás dos "desertos alimentares" (ou dos "pântanos de comida", termo preferido pelo autor). Podem-se compreender os desertos alimentares como lugares nos quais os acessos 
a alimentos nutritivos são difíceis e, consequentemente, onde se encontra diminuição do seu consumo.

Nesse capítulo, é notada a estrutura do ambiente alimentar também encontrada em Duran (2013) e que se divide em macro e microambiente alimentar, bem como em ambiente alimentar institucional. O macroambiente se constitui pela localização e densidade de empreendimentos de alimentação, assim como pela proximidade a trabalho, escolas e residências (GLANZ et al., 2005; CHARREIRE et al, 2010). Já o microambiente alimentar se faz pelas variáveis encontradas a partir dos empreendimentos como preço, qualidade, variedade, disponibilidade, distribuição e propaganda de alimentos (GLANZ et al., 2005; GUSTAFSON; HANKINS; JILCOTT, 2012). O ambiente alimentar institucional, por sua vez, estaria contido em empreendimentos de comercialização de alimentos e nas medidas acerca do microambiente alimentar dentro de escolas e ambientes de trabalho, por exemplo (KELLY; FLOOD; YEATMAN, 2011).

De forma reflexiva, analisando as desigualdades do ambiente e do sistema alimentar, o autor se coloca na sua posição de homem branco que reflete a "branquitude normativa" imperando no sistema alimentar. Ele medita sobre os muitos projetos que são iniciados e controlados por brancos privilegiados, alguns até bem intencionados, mas que são mal informados e mal orientados, quando se pode observar que seus programas ignoram as diferenças culturais e raciais em relação às desigualdades encontradas no sistema alimentar. Broad (2016), inclusive, inclui a CSU nesse contexto, mesmo que a organização tenha incorporado ideias críticas do movimento de justiça ambiental e usado restrições neoliberais no instante em que servia à comunidade.

Nos capítulos terceiro e quarto, cujos respectivos títulos são "In a Community Like This" e "The Youth Food Justice Movement", observa-se a dedicação do autor como ativista e acadêmico. Percebe-se muito do seu envolvimento pessoal nas entrelinhas do texto, principalmente quando ele explora as lutas travadas e as ações bem-sucedidas da CSU para criar um sistema alimentar mais saudável no sul de Los Angeles. Ali ele relata que se usava a comida para discutir com a comunidade local, principalmente 
entre os jovens, como juntar esforços para trabalhar a importância da mudança e da justiça social.

O quinto capítulo, intitulado "From the Black Panthers to the USDA", traz a fascinante história das origens do Partido dos Panteras Negras (BPP - Black Panther Party, na sigla em inglês) e da CSU. Ficam explícitas as tensões internas ao BPP e a existência de tensões externas entre governo e população. Broad (2016) mostra ainda a CSU fazendo o que pode, fincada nos ideais de mudança social, para garantir financiamentos e sobreviver às tensões.

"Competing Visions and the Food Justice Brand" é o sexto e último capítulo do livro. Nele, o autor contrasta a CSU com novos projetos de justiça alimentar que apareceram no sul de Los Angeles, dispondo de apoio midiático e financiamentos consideráveis, porém agindo de maneira mais leve quando se trata de orientação para a mudança social. Aqui também é considerado que o engajamento comunitário nem sempre é tão expressivo.

A obra se apresenta bastante crítica quanto aos projetos de justiça alimentar, classificados pelo autor como esforços claramente defeituosos e liderados por salvadores brancos que, mesmo tendo ganhado a simpatia da CSU, são ainda imperfeitos. Broad (2016) faz, inclusive, recomendações para mudar este panorama e ressalta a importância do lugar de fala nestas questões. Na obra, aparecem muitos insights dirigidos para interessados no uso da comunicação e das mídias para a mudança social, como por exemplo o fato de a organização usar panfletos distribuídos de porta em porta. O uso de baixa tecnologia na divulgação voltada para residentes locais sugere que a CSU precisa se atualizar e inovar. Ao mesmo tempo, Broad (2016) insinua que a desconfiança e a desconexão entre as mídias e as organizações comunitárias podem resultar em oportunidades perdidas. Ele também critica projetos bem-intencionados que afirmam estar resolvendo problemas apenas com comida e, para tanto, tece paralelo entre o que ele chama de "abordagem mágica" à justiça alimentar e a teoria das janelas quebradas em criminologia. De acordo com esta, pequenos sinais de desordem como vandalismo ou vadiagem podem prevenir crimes e instabilidades mais 
sérias (GAU; PRATT, 2010; SOUSA; KELLING, 2006; HARCOURT; LUDWIG, 2006). Assim, veicular imagens de crianças plantando hortas escolares e mostrar a frescura dos produtos disponíveis nas lojas de bairro seriam boas intenções, mas de pouca utilidade se as famílias da comunidade não tiverem acesso a uma cozinha para preparar refeições. Broad (2016) credita a tentativa da CSU de promover conversas sobre alimentos para engajar membros da comunidade em discussões mais amplas sobre justiça racial e econômica.

Entrementes, pode parecer para o leitor que o autor não é muito objetivo em alguns posicionamentos. Pode, inclusive, parecer que outras organizações que são criticadas no texto, por ventura, tenham tido encontros negativos com a CSU - o que implicaria a construção de uma figura de Broad como voluntário apaixonado defendendo sua organização. Contudo, à medida que ele combina seu posicionamento com as observações etnográficas e adiciona as entrevistas com atores diversos, ele se mostra um pesquisador cuidadoso. Assim, mesmo tendo proximidade com a CSU, o leitor de seu livro pode interpretar seus posicionamentos e refletir sobre cada observação sua.

Fica bastante evidente na obra que a CSU tem assumido o compromisso, com graus distintos de sucesso, de continuar lutando para criar um caminho entre os ideais revolucionários, o financiamento neoliberal e as realidades da mídia em prol da justiça alimentar. Na obra, ainda se pode encontrar muitas recomendações feitas a elaboradores e gestores de políticas públicas, a financiadores e a mídias principalmente sobre a necessidade de que todos esses promovam ativamente o interesse público e fujam de narrativas simplistas e demasiadamente estilizadas. Isso fortalece a ideia da desconexão da comunicação vivenciada pelas organizações comunitárias que, muitas vezes, podem ser reduzidas como relações públicas de comunidades. 


\section{REFERÊNCIAS}

BALL-ROKEACH, S. et alli. Understanding individuals in the context of their environment: Communication ecology as a concept and method. In: ANNUAL CONFERENCE OF THE INTERNATIONAL COMMUNICATION ASSOCIATION, 62., 24 to 28 may 2012, Phoenix, Arizona. Anais... Phoenix: [online], 2012.

BROAD, G. M. More Than Just Food: Food Justice and Community Change. Oakland, CA: University of California Press, 2016.

CHARREIRE, H. et alli. Measuring the food environment using geographical information systems: a methodological review. Public Health Nutrition, Cambridge, v. 13, n. 11, p. 1773 - 1785, 2010.

DURAN, A. C. da F. L. Ambiente alimentar urbano em São Paulo, Brasil: avaliação, desigualdades e associação com consumo alimentar. 2013. Tese (Doutorado em Nutrição em Saúde Pública) - Faculdade de Saúde Pública, Universidade de São Paulo, 2013.

GAU, J. M.; PRATT, T. C. Revisiting broken windows theory: Examining the sources of the discriminant validity of perceived disorder and crime. Journal of Criminal Justice, Amasterdam, v. 38, n. 4, p. 758 - 766, 2010.

GLANZ, K. et alli. Healthy nutrition environments: concepts and measures. American Journal of Health Promotion, New York, v. 19, n. 5, p. $330-333,2005$.

GUSTAFSON, A.; HANKINS, S.; JILCOTT, S. Measures of the consumer food store environment: a systematic review of the evidence 2000-2011. Journal of Community Health, Switzerland, v. 37, n. 4, p. 897 - 911, 2012.

HARCOURT, B. E.; LUDWIG, J. Broken windows: New evidence from New York City and a five-city social experiment. University of Chicago Law Review, Chicago, v. 73, p. 271, 2006.

KELLY, B.; FLOOD, V. M.; YEATMAN, H. Measuring local food environments: an overview of available methods and measures. Health \& Place, Amsterdam, v. 17, n. 6, p. 1284 - 1293, 2011.

SOUSA, W. H.; KELLING, G. L. Of "broken windows", criminology, and criminal justice. In: WEISBURD, D.; BRAGA, A. Police Innovation: Contrasting perspectives. Cambridge: Cambridge University Press, 2006. p. $77-97$.

WILKIN, H. et alli. Comparing the communication ecologies of geo-ethnic communities: How people stay on top of their community. The Electronic Journal of Communication, [online], v. 17, n. 1 - 2, 2007. 